\title{
Medical education for the future
}

\author{
Richard Hamilton
}

J R Soc Med 2005;98:208-209

In the words of Dr Alan Greenspan, Chairman of the US Federal Reserve Board, 'the obsolescence of human skills is greater than at any other time in history'. This will be as true of medicine in the 21 st century as in his world of business. Indeed, the two seem set to forge ahead at unprecedented speed. The challenge facing medical education will be to keep pace with a phase of astonishing change.

In fifty years' time the medical students of today will be at or nearing retirement. I wonder how we shall look back on our undergraduate training and the way we were prepared for this radically changing world. Here are some of my guesses about the medical landscape of fifty years hence.

\section{A vision of 2055}

Genomic healthcare is the norm. Genetic tests are used routinely to predict individual susceptibility to disease, and many potential diseases can be stopped in their tracks. A large part of the doctor's training is in the interpretation of genetic tests for disease profiling, and the whole emphasis of medicine has switched from cure to prevention. We know also which genes code for which proteins and a database can be consulted for the 3-D structures of all known proteins. Tissue banks grow new organs from the patients' own cells, and stem-cell treatment for brain disorders such as Parkinson's disease and Alzheimer's disease is routine. In surgery nanotechnologies and robotics have made the major open operation almost extinct, and even minimally invasive procedures such as balloon angioplasty have given way to injection of capsules that can be guided by computer to the affected site. Pharmacogenetics is taught alongside pharmacokinetics, and 'designer drugs' based on the individual's genetic profile are used against specific molecules. With our detailed knowledge of what regulates cell growth, survival and death, cancer can nearly always be brought under control. And our molecular knowledge of the connections between brain, emotion and behaviour has yielded effective approaches to the psychological aspects of disease.

Richard Hamilton, MA, is a fourth year medical student at Sheffield University. Before entering medicine he qualified as a solicitor.
Provision of medical care is now largely private, and health informatics enable patients to shop around for advice and treatment. Patients carry smart cards that include not only details of treatment and images but also genomics and insurance details. Blood samples are analysed on the spot and the results are uploaded to a secure record. Ward rounds are paperless. Hand-held imaging allows general practitioners to view the patient's internal organs, and their interpretations are checked either by comparison with international image datasets or by specialists contacted via secure networks.

Some aspects of the 2055 scene are less cheering. With global warming, new infectious diseases have emerged in geographic zones that were formerly temperate. Though we have vaccines for HIV/AIDS, malaria and tuberculosis, certain infectious diseases are in the ascendant because of treatment resistance. Nor has the world yet freed itself of the hazards of fifty years ago-substance misuse, an influenza pandemic, warfare, bioterrorism. The world population is now 9 billion, and the health inequalities are widening rather than narrowing. In the UK, the number of over-75s has doubled from the 4.5 million of 2005, and average life expectancy is now 80 for men and 85 for women; so medical practice is dominated by the management of chronic disease and longterm care.

What is happening in the medical schools? Apprenticeship has not died, but medical students spend much time in front of screens, dealing with virtual reality, and in skills centres. They train alongside other health workers, and their teachers have been taught to teach to a national core curriculum. Students take large parts of the exams by computer; and they begin to specialize even before graduation. Many of the old clinical skills, such as auscultation, are now redundant, while space medicine for a burgeoning tourist market is taught and sleep medicine is elucidating a third of our lives.

\section{5}

Of course many of these guesses will be wrong. Fifty years ago, ether was still routinely used for anaesthesia and the structure of DNA had only just been discovered; and, until 1953, newly qualified doctors were legally entitled to undertake any form of medical practice without supervision or any requirement for further training. In those days, 
recombinant DNA therapy, minimally invasive surgery and tomographic imaging could hardly have been imagined. Similarly, fifty years hence, the biggest changes are likely to be those not envisioned here.

One thing is for sure, though: medical ethics will come to feature prominently, both in political decision-making and in the design of medical curricula. Even the technologies now in development present huge moral and ethical dilemmas. Human beings have always tampered with the natural world. Now, instead of artificially selecting strains of wheat or breeds of sheep, we have the capacity to alter ourselves, at source, without recourse to natural selection. Some will see this as the march of progress, others as a step into the abyss. But perhaps more than ever, in this coming era of high technology, people will need doctors they can trust; and the necessary qualities of humanity, compassion and professionalism can never be acquired from skill centres or the internet - only by example.

Acknowledgments I thank Dr Chris Roberts and Dr Mike Stein for their thoughts and vision. 